FedUni ResearchOnline

http://researchonline.federation.edu.au

This is the peer-reviewed version of the following article:

Paliadelis, P., Wood, P. (2016) Learning from clinical placement experience:

Analysing nursing students' final reflections in a digital storytelling activity.

Nurse Education in Practice, 20(2016), 39-44.

Which has been published in final form at:

http://doi.org/10.1016/j.nepr.2016.06.005

Copyright $(2016$ Elsevier Ltd. All rights reserved. This manuscript version is made available under the CC-BY-NC-ND 4.0 license http://creativecommons.org/licenses/by-nc$\mathrm{nd} / 4.0 /$ 
Education in Practice

Elsevier Editorial System(tm) for Nurse

Manuscript Draft

Manuscript Number: NEP-D-15-00094R1

Title: LEARNING FROM CLINICAL PLACEMENT EXPERIENCE: ANALYSING NURSING STUDENTS' FINAL REFLECTIONS IN A DIGITAL STORYTELLING ACTIVITY

Article Type: Full length Original Research Article

Keywords: Reflection; digital storytelling; clinical placement; workplace experience; nursing student

Corresponding Author: Prof. Penny Susan Paliadelis, PhD

Corresponding Author's Institution: Federation University Australia

First Author: Penny Susan Paliadelis, PhD

Order of Authors: Penny Susan Paliadelis, PhD; Pamela Wood, PhD

Manuscript Region of Origin: AUSTRALIA

Abstract: This paper reports on the learning potential of a reflective activity undertaken by final year nursing students, in which they were asked to recount two meaningful events that occurred during their clinical placements over the duration of their 3-year nursing degree program and reflect on how these events contributed to their learning to become beginning level Registered Nurses ( RNs). This descriptive qualitative study gathered narratives from 92 students as individual postings in an online forum created within the University's learning management system. An analysis of the students' reflections are the focus of this paper particularly in relation to the value of reflecting on the identified events. Four themes emerged that clearly highlight the way in which these students interpreted and learned from both positive and negative clinical experiences, their strong desire to fit into their new role and their ability to re-imagine how they might respond to clinical events when they become Registered Nurses. The findings of this study may contribute to developing nursing curricula that better prepares final year students for the realities of practice. 
Cover letter re manuscript titled:

\section{LEARNING FROM CLINICAL PLACEMENT EXPERIENCE: ANALYSING NURSING STUDENTS' FINAL REFLECTIONS IN A DIGITAL STORYTELLING ACTIVITY}

\section{Dear Editor}

We wish to confirm that all authors meet the criteria for authorship, have approved the final article and that all those entitled to authorship are listed as authors. We also confirm that this work is original and has not previously been published elsewhere (either partly or totally), and is not in the process of being considered for publication in another journal.

Yours sincerely

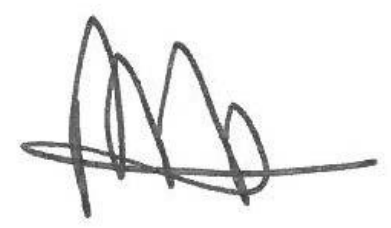

Professor Penny Paliadelis (corresponding author) 


\section{Title: LEARNING FROM CLINICAL PLACEMENT EXPERIENCE: ANALYSING NURSING STUDENTS' FINAL REFLECTIONS IN A DIGITAL STORYTELLING ACTIVITY}

Thank you to the reviewers' for their valuable feedback, the following table provides a summary of the changes made to the manuscript:

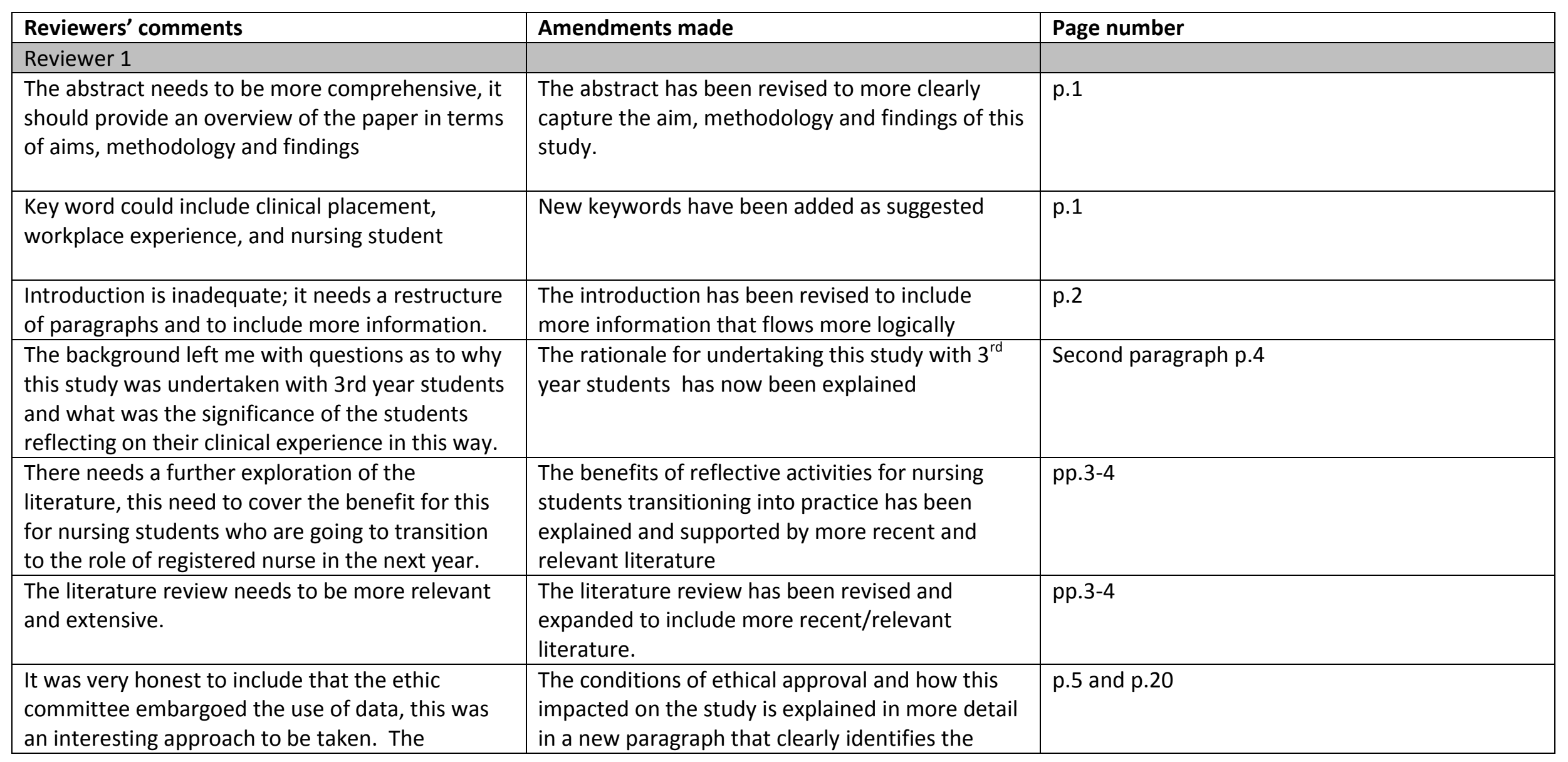




\begin{tabular}{|c|c|c|}
\hline $\begin{array}{l}\text { statement about the stories not being able to be } \\
\text { explored in-depth with students, is misleading, I } \\
\text { believe they are talking about the restriction they } \\
\text { have from the ethics committee, however they } \\
\text { either needed to do this to have rigour in their } \\
\text { methodology or the application of the survey and } \\
\text { methodology is sound in its own right. }\end{array}$ & study limitation. & \\
\hline $\begin{array}{l}\text { The results section provides interesting and } \\
\text { appropriate information, it does not fit with the } \\
\text { introduction and background, there needs to be } \\
\text { better synergy with this as an overall story. }\end{array}$ & $\begin{array}{l}\text { As part of the revisions of the introduction and } \\
\text { background sections and review of the results } \\
\text { section, the coherence of these parts of the paper } \\
\text { have been strengthened, by more closely aligning } \\
\text { the literature reviewed with the results. }\end{array}$ & pp.1-4 \\
\hline $\begin{array}{l}\text { The discussion is good, literature used in the } \\
\text { discussion should have been introduced in the } \\
\text { background as it does not currently flow well. }\end{array}$ & As above, this has been rectified. & pp.3-4 \\
\hline A good conclusion & Thank you & \\
\hline $\begin{array}{l}\text { The references included are good, I believe there } \\
\text { are more current and relevant references that } \\
\text { could be included within this paper. }\end{array}$ & $\begin{array}{l}\text { More recent and relevant literature has been } \\
\text { added into the introduction and background } \\
\text { sections. }\end{array}$ & pp. 1-4 \\
\hline $\begin{array}{l}\text { I think this is a relevant paper however in its } \\
\text { current form I do not think it adds new } \\
\text { information to what is already known about 3rd } \\
\text { year nursing student experiences in clinical } \\
\text { placement. I think it does provide information on } \\
\text { the use of storytelling. }\end{array}$ & $\begin{array}{l}\text { The focus of this paper has been explained in } \\
\text { more detail to demonstrate how digital } \\
\text { storytelling can prompt reflection which in turn } \\
\text { can assist in the transition process from student } \\
\text { to RN. }\end{array}$ & pp1-4 and 16-19 \\
\hline \multicolumn{3}{|l|}{ Reviewer 2} \\
\hline $\begin{array}{l}\text { In the beginning of the introduction (page } 1 \text { ) I } \\
\text { would like the text to be supported by references }\end{array}$ & $\begin{array}{l}\text { Relevant references have been added as } \\
\text { suggested. }\end{array}$ & p.1 \\
\hline
\end{tabular}




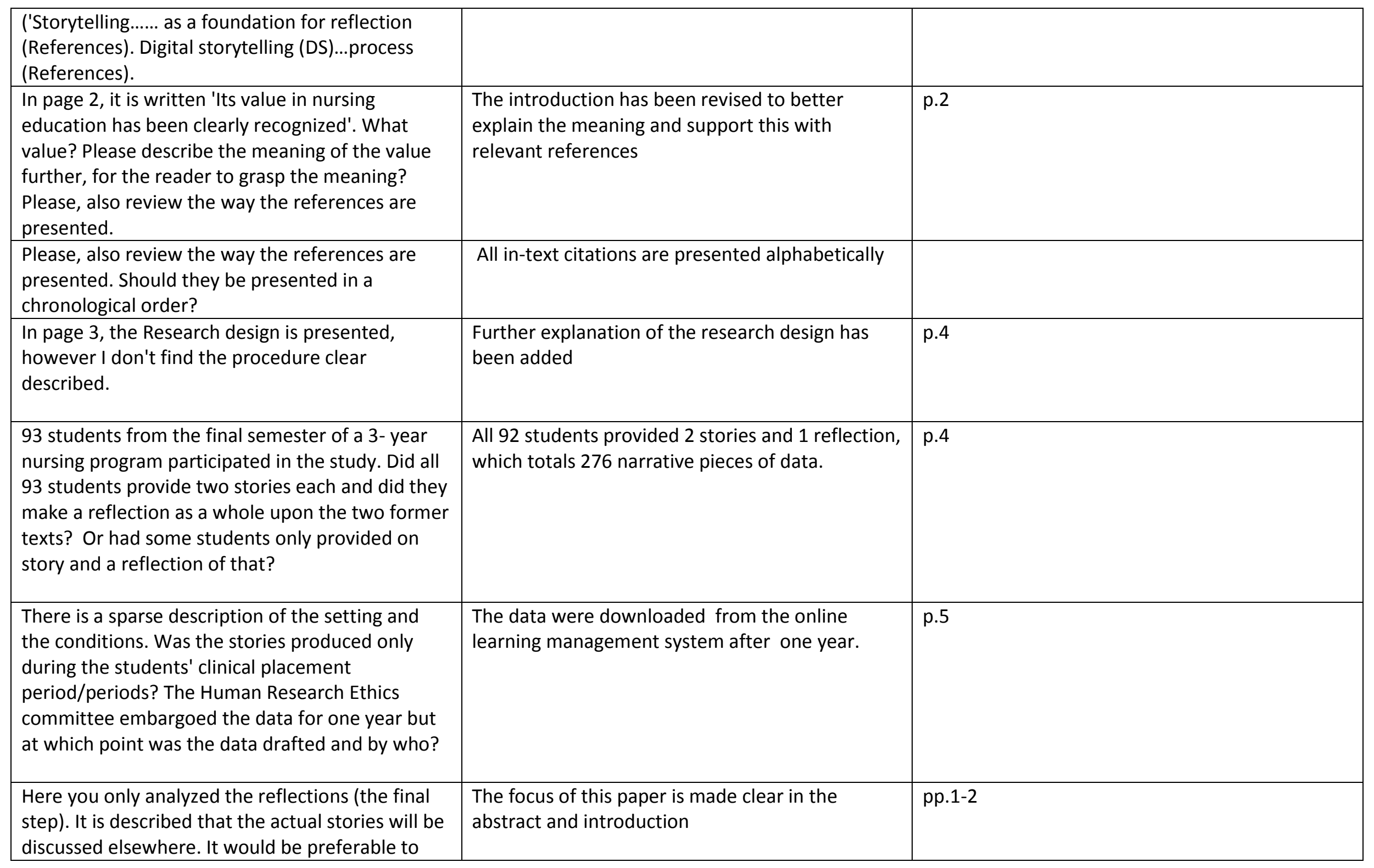




\begin{tabular}{|c|c|c|}
\hline describe that as unsubmitted data. & & \\
\hline $\begin{array}{l}\text { Have some ethical consideration been reflected } \\
\text { on due to this study? Please, present your } \\
\text { considerations. }\end{array}$ & $\begin{array}{l}\text { The ethical consideration regarding protecting } \\
\text { participant anonymity and any potential to link } \\
\text { this data to specific placement locations has been } \\
\text { described, as this was 'to reduce any potential risk } \\
\text { that data could be linked to any specific student, } \\
\text { clinical setting or situation'. }\end{array}$ & p.5 \\
\hline $\begin{array}{l}\text { The Results are distinct presented but the } \\
\text { subtheme 'Learning form difficulty' is not fully } \\
\text { captioned. Please be aware of that this text also } \\
\text { describes positive incidents. }\end{array}$ & $\begin{array}{l}\text { Themes have been revised and sub-themes } \\
\text { removed }\end{array}$ & p.6-16 \\
\hline $\begin{array}{l}\text { The discussion is interesting and well balanced. In } \\
\text { the limit paragraph the results are discussed but } \\
\text { not the method used, which would be preferable }\end{array}$ & $\begin{array}{l}\text { There were no specific limitations identified in the } \\
\text { methodology }\end{array}$ & \\
\hline $\begin{array}{l}\text { In the conclusion there is a description of 'the } \\
\text { project' (page 18) - that is not mentioned before. } \\
\text { Please, make either change in the text here or } \\
\text { earlier in order to be congruent in the manuscript. }\end{array}$ & This has been revised to read 'research study' & p.20 \\
\hline
\end{tabular}




\section{LEARNING FROM CLINICAL PLACEMENT EXPERIENCE: ANALYSING \\ NURSING STUDENTS' FINAL REFLECTIONS IN A DIGITAL STORYTELLING \\ ACTIVITY}

Authors:

Professor Penny Paliadelis ${ }^{\mathrm{a}}$

Associate Professor Pamela Wood ${ }^{\mathrm{b}}$

${ }^{a}$ Corresponding author - Executive Dean, Faculty of Health, Federation University Australia, PO Box 663, Ballarat, VIC, Australia 3353. Email: p.paliadelis@ federation.edu.au, Tel: +61353276445, Mob:+61400417494

${ }^{\mathrm{b}}$ Associate Dean (Research), Faculty of Health, Federation University Australia, PO Box 663, Ballarat, VIC, Australia 3353. Email: pamela.wood@federation.edu.au

Word count:

Without references $\quad 4647$

With references $\quad 5750$ 


\title{
LEARNING FROM CLINICAL PLACEMENT EXPERIENCE: ANALYSING NURSING STUDENTS' FINAL REFLECTIONS IN A DIGITAL STORYTELLING ACTIVITY
}

\begin{abstract}
$\underline{\text { ABSTRACT }}$
This paper reports on the learning potential of a reflective activity undertaken by final year nursing students, in which they were asked to recount two meaningful events that occurred during their clinical placements over the duration of their 3-year nursing degree program and reflect on how these events contributed to their learning to become beginning level Registered Nurses ( RNs). The students were required to describe the two meaningful incidents and then reflect on how these contributed to their learning for their future practice as beginning level registered nurses. This descriptive qualitative study gathered narratives from 92 students as individual postings in an online forum created within the University's learning management system. The analysis of the students' reflections are the focus of this paper particularly in relation to the value of reflecting on the identified events. Four themes emerged that clearly highlight the way in which these students interpreted and learned from both positive and negative clinical experiences, their strong desire to fit into their new role and their ability to contribute to have been analysed and demonstrate that students understand the ideals as well as the realities of practice, and that reflecting on these incidents encouraged them to to-re-imagine how they might respond to such events when they become Registered Nurses . The findings of this study may contribute to developing nursing curricula that better prepares final year students for the realities of practice.
\end{abstract}

\section{$\underline{\text { KEYWORDS }}$}

Reflection; digital storytelling; clinical placement; workplace experience; nursing student 


\section{INTRODUCTION}

Storytelling is a powerful education tool widely recognised in the literature (Kearney 2011; Stacey \& Hardy 2011). Brown (2015) suggests that 'If you want someone to remember something important, tell them a story about it.' According to Kirk and Pitches (2013) storytelling can promote deep learning by prompting reflection on practice. As Dewey (1997) explained humans learn best by reflecting on their experiences. Nurses engage with stories from patients and colleagues on a daily basis and use these to reflect on how they relate to practice issues (Christiansen, 2011;Stacey \& Hardy 2011). , or can recount their own stories as a foundation for reflection. Digital storytelling (DS) is a new variant of this reflective process, in which technology can be harnessed to create a safe and engaging space for storytellers to share and reflect on their experiences (Hlalele \& Brexa 2015). DS is a relatively new storytelling mode but its pedagogical value has been demonstrated (Eisenhauer , 2012), particularly its capacity to promote reflection and deep learning (Mimirinis \& Bhattacharya, 2007). The variety of DS forms can be captured as written text, audio and visual formats, and online conversations (Kirk \& Pitches, 2013)-The aim of the study discussed in this paper was to use an online learning platform to gather final year nursing students' stories from clinical practice to better understand what was meaningful for them and whether reflecting on the events they described contributed to learning for future practice situations. and reflective digital storytelling about two clinical placement experiences. Students recounted and reflected on their experiences in three online forum postings during their final semester of study in a nursing degree program in an Australian university. This article reports the results of an analysis of the students' reflections as they anticipated their transition to beginning level registered nurse $(\mathrm{RN})$ practice. 


\section{BACKGROUND}

Storytelling has been used as a powerful educational medium in many professions (Kirk et al., 2013). Its value in nursing education has been clearly recognised (Crookes et al., 2013; Diekelmann, 2001; Haigh \& Hardy, 2011; Ironside, 2006; 2002; Moon \& Fowler, 2008; Stacey and Hardy 2011; Wood, 2014; Young, 2007)as an educational tool and as means of supporting students to reflect on and re-imagine practice (Paliadelis et al., 2015; Wood, 2014). Reflection is a significant aspect of understanding and developing practice (Mann et al., 2009; Moon, 2004; Schön, 1987) and personal narratives of reflection on previous events can deepen emotional awareness (Arielli, 2013; Edwards, 2014; Hunter \& Hunter, 2006) and help with making informed choices that build on experiences (Dewey 1997). In the 1980s Melia (1984) made the point that nurses' ability to socialise into the profession required a compromise between their educational and service (clinical) experiences, in this paper we suggest that reflecting on clinical events can assist in this process. Schwind et al. (2011:225) state that 'by telling, reflecting and reconstructing events we gain the potential to transform our lives, and consequently the lives of those in our care'. Denzin (2014:53) also suggests that reflecting on events as stories can lead to illuminative or 're-lived epiphanies', which may be turning points in people's lives and provide the opportunity to better understand our interpretations. The notion that reflection assists in reconstructing events was of significance when considering nursing students reflections of clinical experiences and what such reflections might contribute to their learning for future practice. The challenge for educators is to understand how best to use refection to prompt learning and improve practice (Gidman 2013). Callens and Elen (2015) explain that effective reflective learning is evident when the reflective narrative includes emotional, technical, moral and political elements.

Patients' digital stories have been used with significant effect (Christiansen, 2011). Gidman (2013) described a project that gathered patients' stories to prompt caregivers to 
understand and connect with the consumers' journey. Students' own digital stories are often used for deep learning and reflection on practice (Paliadelis, et al., 2014; Stacey \& Hardy, 2011).

This study analysed final year nursing students' digital stories submitted as reflective narratives online in the final semester of a 3 year nursing program. Stacey and Hardy (2011:164) found the use of digital stories to prompt reflection is particularly relevant for novice nurses and these authors encourage the use of storytelling to 'enable student to be better prepared for the real world of clinical practice'. Jokelainen et al (2011) and LevettJones et al. (2007) add that clinical learning environments must be supportive if they are to assist novice nurses to 'fit in' to a new work environment. Walker et al. (2013) also stress the importance of providing support for novice nurses to enable them to become work ready and develop the level of resilience and flexibility needed to cope with the complexities of the modern health workplace.

Without positive role-modelling and a supportive learning environment novice nurses are at risk of experiencing anxiety and negativity and in the workplace, which may even result in them leaving the profession prematurely (Jackson et al. 2011; Li et al 2013; Stacey \& Hardy 2011). The aim of the study discussed in this paper was to explore whether reflecting on previous clinical events could better support students to make the transition into practice and so final year students were the target population. Each story comprised three pestings; in the first twe Students were given a structured format in which to recounted two situation or event from their previous clinical placement experiences throughout their program that was meaningful to their practice and development as a nurse. In a final posting, they were asked to reflect on both of these events and identify the elements of the events that they felt would 
shape their future practice as beginning RNs. It is these reflections that are the focus of this paper.

\section{RESEARCH DESIGN}

This study used a qualitative descriptive methodology to analyse the students' stories and reflections. Sandelowski (2000:336) explained that this is a valuable methodology when researchers want to 'stay closer to their data and to the surface of words and events. Surface readings should not be considered superficial, or trivial and worthless'. The two authers whe developed the learning activity gained ethical approval for the project gained ethical approval from the-Ethical approval for this study was granted by the Human Research Ethics Committee of the university. Following completion and grading of the students' work, all students were given an information sheet and consent form, and invited to allow their data to be used for this study; 92 of the 123 students consented to their de-identified stories and reflections being used for this study.

The Human Research Ethics Committee embargoed use of the data for one year following data collection, to reduce any potential risk that data could be linked to any specific student, clinical setting or situation. After 1 year the archived data was downloaded from the learning management system and analysed thematically.

As the stories could not be explored in more depth with the students, the The most appropriate research design was a qualitative descriptive study, based on a thematic analysis of the online postings that formed the research materiat

The students' reflections were analysed by each researcher separately, to identify major themes in the reflective narratives. the focus or content of stories, and students' reflections on 
these stories. The analyses were then discussed as a group, and where any differences occurred, the best representation of the themes in the reflections was agreed.

The quality and depth of the reflections meant that a significant amount of data was analysed. Students reflected on a number of aspects of the events they described, identifying a range of a wide range of sitmations or events related to ethical, professional, technical, political and clinical issues they encountered on clinical placement. The depth of the reflections were consistent with Callens and Elen's ( 2015) understanding of what constitutes a critical reflection. While an analysis of the content of the two clinical events on which the student reflections were based is beyond the scope of this paper, focusing on the reflective narratives highlights the core issues the students focused on in their stories. This article focuses only on the students' reflections on their two stories and how these might transtate into learning for their future roles as beginning RNs.

\section{$\underline{\text { RESULTS }}$}

This section describes the four themes that emerged from the thematic analysis of the students' reflections: 1) recognising the impact of experience, 2) understanding workplace complexity, 3) confirming career choices, and 4) transitioning to RN practice.

\section{Theme 1:Recognising the impact of experience}

This theme captures the participants' reflections on the significance of the events they described, and what these may mean for their future practice. The first sub theme focuses on what students clearly learned from the learning gained from a number of a range of a range of difficult situations and often re-imagined the events, based on what they learned from them. 
The participants also wrote about how they developed an awareness of the value of reflecting on their experiences to inform future practice.

Many of the students' reflections made it clear that the events they chose to describe left a 'lasting impression'. These were predominantly stories of difficult situations or events. Students used powerful descriptors in relating them, such as 'confronting', 'extraordinary', 'alarming' and 'intimidating'. Students wrote that they experienced 'shock, puzzlement and confusion', or felt 'really scared' or 'astounded', as part of their reflections on the significance of the chosen events.

Students frequently remarked that difficult events or situations was ultimately positive for learning. One believed that it was because it caused a 'strong emotional reaction'. The following comments show a consistent thread in students' recognition of what they learned from negative experiences:

The clinical event was a negative experience but has influenced my nursing practice in a positive way.

These experiences highlighted not only the type of nurse I want to be, but more importantly the type of nurse "I do not want to be", therefore I have chosen to extract the positives about what I have gained, rather than stew or dwell on what had taken place.

Even if the professional practice I encounter is not professional and does not adhere to any applicable policies or processes, it will still inform my future practice because I am learning what not to do. 
The two incidents influenced and informed my view not only on how nurses in general should deliver care but how I personally want to deliver care, how I would manage such situations, and the kind of nurse I would like to be.

From these two unacceptable cases I have learnt such fundamental concepts of nursing, especially involving patient advocacy. I have learnt to have a voice and an opinion, to speak when I do not think something is acceptable.

A number of positive incidents were also captured. As one student commented:

Although I had experienced and witnessed bad clinical incidents they have [been] outweighed by copious amazingly good experiences. To me, I have learnt most from the bad experiences than those of good but have been inspired by amazing nurses who I wish I could be like one day.

In their reflections many of the students re-imagined the events and identified skills or attributes they felt they needed to become effective nurses. Advocacy was a significant factor discussed by many of the students. In one of the narratives a student questioned her motives for not speaking up:

Ifelt fearful of the repercussions that might lie ahead when challenging someone in a higher position. With this said, I can now see that I only had my own interest at heart, when I should have been a better advocate and questioned the care that was received.

Similarly others said: 
As a student in this situation it is hard to speak up and say something as we are concerned of the ramifications that may occur. However, on reflection I realise that the patient's health may have been at risk, and I probably should have reported it.

I was freaking out on the inside ... I was extremely uncomfortable. I didn't want to be labelled the student nurse that thought she knew better than the staff.

One participant wondered why it was difficult to speak out when the situation involved another nurse.

I have never had a problem advocating for patients with medical officers or other members of the interdisciplinary team and pride myself on this. However, when it came to confronting a fellow nursing colleague about their behaviour, I was unable to do so. I wonder if this is to do with peer pressure, or the cultural norms of the nursing profession. Do we stick together because we are on the same "side"? ... It is an area I need to reflect on more thoroughly and come to understand what my feelings were ... This is not a trait I wish to take into my beginning practice.

A number of the other reflections enabled students to consider whether their initial reaction was the right one or needed to be modified.

I may have conceived these actions as inappropriate due to being shocked ... [and] this may have resulted in incorrectly perceiving this in a negative or incorrect manner.

One incident made me feel as though I had caused the medication error. I have reflected upon the experience and realised that I was not to blame. 
Overall, the students noted that a change in their approach to practice. reflecting on clinical placement events gave them 'confidence and courage' instead of being 'an overwhelmed student in the background with a sense of powerlessness'. Learning from RNs' 'strengths and making them your own', and acknowledging their own 'mistakes and weaknesses', were seen as highly valuable outcomes of reflecting. Students displayed evidence of experiencing re-lived epiphanies, as described by Denzin (2014).

Students also commented that the learning activity had reinforced for them the value of reflection. One said:

I have just had a light bulb moment. I can now come to understand the importance of reflective journal writing....I have not only learnt from this exercise in regards the clinical incidents, I have learnt the importance of reflection.

\section{Theme 2: Understanding workplace complexity}

In the second theme, students focused on the complexity of the workplace and the organisational factors influencing practice. If their stories described mistakes (such as potential medication errors) or what they perceived as unprofessional behaviour (such as disrespect to patients), they acknowledged that these were not necessarily deliberate and that many factors contributed to these incidents:

I don't believe the staff intentionally meant to be disrespectful; they were being task oriented and did not identify their behaviour as detrimental to achieving optimal care.

Patient load, time constraints and staffing issues were frequently mentioned as contributing factors: 
Major precipitating factors in this event were increased workload and inadequate staffing.

It is also essential that I take into consideration the reasons as to why these incidents occurred, such as patient loads and inadequate staffing, time restraints and lack of education.

One student thought an incident might have been 'the result of something external to work that the nurse brought with them' and that if the nurse had had 'an opportunity to disclose and discuss their stresses', it might not have occurred. However, personal contributing factors were not always seen in this light:

Reflecting on the situation and going through the events it was evident that my registered nurse not only had a heavy patient load she was extremely exhausted from the night before and stated she had little sleep if any at all.... She did not carry out her duty of care....Her best on the day was not good enough and could have resulted in death. Duty of care to herself and her patients was compromised and she was only lucky this mistake was not deadly.

\section{Theme 3: Confirming career choices}

The third theme captures the participants' commitment to the nursing profession. For many of the students this was about being inspired by others during their placements, while for some it was about acknowledging any doubts about their career choice and about developing confidence in their ability to function as beginning level RNs.

Students sometimes reflected that their clinical placement experiences confirmed their decision to become a nurse. This was often due to an 'inspiring' situation or registered nurse.

It was inspiring and something I hope I can take with me wherever I go. 
I think at some stage of our working, or student, life we are touched by someone that truly inspires us to forge ahead and strive to obtain the highest of goals.

This is the kind of nurse I want to be.

One student's experience of a medical emergency was a significant moment in confirming the choice of nursing as a career:

One of the professional issues I encountered was an extremely positive experience for me and one I am sure in years from now I will look back and it will stick out as a major learning curve and point in my life that I was sure a career in nursing was exactly what I wanted to do.

Sometimes an incident in clinical placement led students to reflect on whether they had made the right their career choice.

It made me question the reason as to why I wanted to be a registered nurse.

I would find myself questioning why it was that I was studying the degree in the first place! This is a blunt statement to make, however I feel it is a necessary component to outline my experiences as a student nurse.

However, as another student reflected; 'helped me gain a positive hope for my futture eareer'.

\section{Theme 4: Transitioning to RN practice}

It was very clear in all the reflections that these students understood some of the challenges they would face as they commenced a nursing career. For some, the responsibilities they would assume as RNs were rather daunting. However, the reflections suggested that the participants were acutely aware of the unpredictability of modern nursing 
practice and the value of reflecting on events to inform future practice. Understandably these participants also commented on their nervousness about 'fitting in' to the clinical work environment and developing a sense of belonging. They also looked forward to their role in supporting nursing students in the future.

Reflecting on clinical placement events gave these students a sense of the expectations and the 'not so obvious challenges' of commencing RN practice. They worried about the degree of responsibility they would have - 'people's lives will be in my hands' - as well as how quickly and easily clinical situations could change and 'lives can be lost'.

Observing these clinical incidents has shown to me how precious life is and how unexpectedly things may evolve.

The students identified that reflecting on their experiences helped them to developed a clear understanding that flexibility, adaptability and a calm approach were needed in managing rapidly changing situations.

Nursing is a profession with many surprises and it's important as a RN to be flexible and adapt to changing situations.

Through witnessing this event unfold and acknowledging all the factors associated I realised there is immense value in just stopping and taking a deep breath. Taking a deep breath, centring myself, taking the time to prioritise care and the tasks at hand.

Several were 'fearful' of the responsibility and accountability of RN practice.

Transitioning from a student nurse to a Registered Nurse $(R N)$ can be quite scary and quite concerning in regards to undertaking an autonomous role and developing 
professional credibility. Expectations of a new graduate nurse can be quite overwhelming.

Overall, reflection on clinical placement experiences supported students 'to be the confident, capable and professional nurse' they were aspiring to be. Many were confident that they would successfully transition to $\mathrm{RN}$ practice.

I now understand I am a strong and capable individual who is confident in my ability to nurse and care for patients professionally.

They also realised the incremental nature of developing skills and confidence.

Also I find as an important aspect as a newly Registered Nurse is to appreciate that out knowledge base is limited and will constantly develop with exposure to the world of nursing. It is important that at times it is appropriate to question if unsure why things are occurring.

I almost made myself physically sick because I was so worried that I would be judged on the amount of time it takes me... I have started to become less critical of myself and ... I am hoping that I will challenge my thought processes as my practice develops.

Students reflected on the difference between being a student or an RN in a practice context. They particularly emphasised that they needed to be accepted before trying to influence change. 'Fitting in' was an important first step. The students felt that it was very important to importantIt was necessary to accept a new workplace wherever it was, and 'fit in with the culture of the facility'. 
Fitting in is almost a core element to successful progression and professional development as a new nurse.

I acknowledge that it will take me a month or so to settle into my new work environment but I am confident that I will then be able to speak up about issues that concern me.

They knew that as students they had responsibility 'to identify wrong practices' but believed that as an RN they would have 'a greater level of power to change and apply the appropriate practice'. Nevertheless, they felt that 'gumption' would be needed to advocate for patients or practice changes:

As new RNs they might sometimes 'doubt [their] clinical knowledge and confidence' and therefore needed strategies to manage this and support to advocate for changes. One strategy was to 'look for a group of mentors' with similar values who could 'assist and guide' their professional development and practice. They needed, for example, to 'form relationships with peers, prioritise and be organised', to 'listen and be confident in interacting with other members of staff' and 'continue to learn'. Many students identified particular skills they wished to develop further in their beginning RN practice, such as being assertive.

In particular, all the students reflected on how, as RNs, they hoped to work with and inspire nursing students. They believed their own experience on clinical placement would help them to interact effectively with students. They knew the 'pressures' students faced so would 'help relieve these stresses'. From this, they emphasised several aspects: 
This incident has taught me the importance of communicating with the student, discovering their thoughts and feelings toward the placement and working together to achieve identified learning objectives.

Students needed to feel 'part of the team' and that they could 'share their knowledge and ideas without repercussions'.

I know now through this reflection that I can be a good mentor because I can reflect upon my own feelings as a student nurse and hopefully make other students' experiences more positive.

An important point was not to 'put a student in a position which you never felt comfortable in when you were a student'. Several students commented that their experience had made them think that 'nurses eat their young'.

This experience has left me with a feeling that I still find uncomfortable, when thinking about the incident. After this experience I understand the phrase "nurses eat their young".

I will never treat a student the way I was treated ... The saying "nurses eat their young", I heard this many times and have even said it myself.

\section{$\underline{\text { DISCUSSION }}$}

This discussion links the themes identified elements in in the students' final reflections with the literature on clinical learning and work readiness, and considers the value of reflective storytelling to prompt learning.

\section{$\underline{\text { Reflections on clinical placement }}$}


The themes that emerged from the students' reflections focused on the overall impact of the clinical placement events they described, and their insights into the realities of the workplace, choice of nursing as a career, and transition to beginning RN practice, including the importance of 'fitting in'. These clearly resonate with themes identifed in relevant literature.

Students' comments on supportive and unsupportive clinical learning environments are reflected in a number of studies on clinical placement experiences which note that a supportive learning environment is a key feature in facilitating students' learning (Jokelainen et al., 2011; Levett-Jones et al., 2007). As with students' comments in our study, the systematic review of clinical placement mentoring by Jokelainen et al (2011) identified the importance of attending to students as individual learners to understand their learning needs. Similarly, the mutual relationship between student and mentor was important. This relates closely to students' comments on the significance of inspiring role models. However, in our study the students also strongly believed that negative role models could have a positive influence on their practice and they demonstrated how reflections on negative events allowed them to re-imagine them more positively. Their reaction to what they perceived as poor practice or disrespectful work relationships supports Kirk et al (2013) findings that such events can prompt 'professional shame'. As Hunter and Hunter (2006) have noted, reflection supports students to discern their own style of practice and is therefore an important aspect of role identity and acquisition.

Students had concerns about the uncertainty of the workplace, seen for example in the need for rapid and flexible responses to changing patient conditions, and they recognised the need to manage these situations effectively. This links with Walker et al's (2013) description of resilience and flexibility as personal characteristics of work readiness. Students' 
acknowledgement of the complexity of the workplace and the impact of patient load, time constraints and inadequate staffing, also connects with Walker et al's (2013) description of organisational acumen as another key feature of work readiness. Several students noted that clinical placement experiences, particularly inspiring role models or satisfaction with their own practice, confirmed their decision to enter nursing as a career. As Jokelainen et al (2011) found, mentoring by positive role models strengthens student's development of professional attributes and identity. Some participants indicated they felt some doubts about their choice of career. This is not unexpected given that there is significant evidence in the literature that the global nursing shortage is partly attributed to attrition of nurses from the workforce due to staff shortages, poor skill mix and job strain (Li et al., 2013).

An important aspect of students' reflections is their anticipation of the transition to beginning RN practice, that identified clear concern about the need to 'fit in'. Building on the work of Melia (1984), Levett-Jones et al's (2007) study of belongingness in clinical placement also emphasised the importance of students' need for connectedness and fit. This links with Walker et al's (2013) description of social intelligence as a key feature of work readiness, including effective communication, teamwork and management of conflict. Students' reflections indicated that they had identified strategies they hoped to use to support the balance between fitting in and making changes, including finding mentors and likeminded colleagues. Similarly, Walker et al (2013) described the importance of seeking support as an element in work readiness.

Students strongly identified the importance of being a good mentor and role model to students in their future RN practice. Jokelainen et al (2011) noted that 'students want to be treated as individuals and colleagues during placement learning' (p.2864) and that achieving a degree of collegiality is desirable within the mentoring relationship. This is clear in 
students' reflections in our study. However, their comments were based more often on negative experiences than on examples of positive role models. Students felt that reflecting on difficult clinical placement experiences enabled them to identify how they could be better mentors for future students. They would communicate with students, consider their individual goals and help them feel part of the team. Their shock at being on the receiving end of disrespectful or abusive behaviour from nurses and others is reflected in other studies (Jackson et al., 2011; Stacey \& Hardy 2011) and is part of the emotional work arising in clinical placement experience (Arielli, 2013). Students did not want to belong to a profession that 'eats its young'. This is recognised as an issue within nursing and is related in the literature to horizontal violence, bullying and burnout ( Kelly \& Ahern, 2009).

Literature on reflective storytelling, including digital storytelling, identifies a range of benefits (Haigh \& Hardy, 2011; Kearney 2011; Mimirinis \& Bhattacharya, 2007; Stacey \& Hardy 2011). Particularly relevant to this study is that telling stories and then reflecting on their meaning enabled these students to make sense of their experiences (Moon, 2004). As suggested by Stacey and Hardy (2011) and Schwind (2011), and based on the earlier work of Dewey (1997) reflecting on our experiences provides opportunities to shape future practice. in this case the situations or events they encountered in clinical placement. Students could also vent their feelings in a supportive and safe atmosphere and gain emotional clarification (Hunter \& Hunter, 2006). The iterative nature of this digital storytelling and reflective learning activity, provided an opportunity for these students to with three sequential pestings two stories and a final reflection strengthened its capacity learn lessons they considered valuable for their future practice (Moon, 2004; Moon \& Fowler, 2008). The great majority of these students showed a deep engagement in reflecting on their stories. They included a range of emotional, technical, moral and political elements in their reflection ,which Callen and Elan (2015) suggest demonstrates deep and effective reflection. eommenting on describing 
their struggle with situations or events, or with their responses to these. While Moon and Fowler (2008) warn that when recalling past events students might modify their accounts to meet suit teacher expectations, in this study the students' reflections contained both positive and negative appraisals of their performance. In this study, the content of the students' stories were not 'graded' and students needed only to show that they had engaged reflectively with their stories in order to pass this task. As Moon and Fowler (2008) noted, 'the very act of telling [a story] has educational value and may be more significant than the content' (p.234). In this study we suggest that this was certainly the case. In addition, the authenticity of students' stories and reflections, and their willingness to have them used for this study, indicates they were not trying to merely provide what they thought lecturers were expecting.

Mann et al's (2009) systematic review of reflection in health profession education identified reflection as an essential characteristic of professional competence, while Schwind et al (2013) suggest that the ability to reflect is vital in helping professions such as nursing. Students' reflections in this study demonstrated that they had engaged effectively with their stories of clinical placement events and had learnt from them in ways that would inform their beginning practice as RNs.

The main limitation of this study is that because this study drew on text-based narratives that were entered into an online learning management system by final year nursing students and the use of the data was embargoed for 12 months, no further discussion or clarification was possible with the participants about their narratives. However, the students' online postings provided rich research material for this qualitative descriptive study.

\section{$\underline{\text { CONCLUSION }}$}

This paper described a research study in which the participants described two events of their choosing from their clinical experiences and reflected on what these events taught them 
in relation to making the transition from student to registered nurse $\cdot$ In this study the participants posted their stories and reflections online and the findings suggest that this was an appropriate medium for the students to share two meaningful experiences and reflect on what these contributed to their learning for their future practice. It is suggested that this approach allowed the participating students to consider the links between their knowledge base, their individual experiences and the realities of clinical practice, as across all the stories it was clear that students had thought deeply about the events they described and reflected on how these might shape their practice as beginning level RNs.

\section{$\underline{\text { REFERENCES }}$}

Arielli, D., 2013. Emotional work and diversity in clinical placements of nursing students. Journal of Nursing Scholarship 45 (2), 192-201.

Brown, S. 2015. The power of story. Computer. September, 82-83.

Callens, C. \& Elan, J. 2015. Does a structured methodology support pre-service teachers more to reflect critically than an unstructured? Reflective Practice 16(5), 609-622.

Christiansen A., 2011. Storytelling and professional learning: A phenomenographic study of students' experience of patient digital stories in nurse education. Nurse Education Today 31, 289-293.

Crookes K., Crookes P. \& Walsh, K., 2013. Meaningful and engaging teaching techniques for student nurses: A literature review. Nurse Education in Practice 13 (4), 239243.

Denzin N., 2014. Interpretive Autoethnography, second ed. Sage, Los Angeles. 
Dewey, J. (1997). Experience and education. New York, NY: Touchstone Edition.

\section{(Original}

work published 1938)

Diekelmann N., 2001. Narrative pedagogy: Heideggerian hermeneutical analyses of lived experiences of students, teachers, and clinicians. Advances in Nursing Science 23 (3), 53-71.

Edwards S.L., 2014. Using personal narrative to deepen emotional awareness of practice. Nursing Standard 28 (50), 46-51.

Eisenhauer J., 2012. Behind closed doors: The pedagogy and interventionist practice of digital storytelling. Journal of Curriculum \& Pedagogy 9 (1), 7-15.

Gidman G., 2013. Listening to stories: Valuing knowledge from patient experiences. Nurse Education in Practice 13 (3), 192-196.

Haigh C., Hardy P., 2011. Tell me a story - a conceptual exploration of storytelling in healthcare education. Nurse Education Today 31, 408-411.

Hlalele, D. \& Brexa, J. 2015. Challenging the narrative of gender socialisation: Digital storytelling as an engaged methodology for the empowerment of girls and young women. Agenda, 29(3), 79-88.

Hunter L.P., Hunter L.A., 2006. Storytelling as an educational strategy for midwifery students. Journal of Midwifery \& Women's Health 51 (4), 273-278.

Ironside P.M., 2006. Using narrative pedagogy: Learning and practising interpretive thinking. Journal of Advanced Nursing 55 (4), 478-486. 
Jackson, D., Hutchinson, M., Everett, B., Mannix, J., Peters, K., Weaver, R. \& Salamonson, Y., 2011. Struggling for legitimacy: Nursing students' stories of organisational aggression, resilience and resistance. Nursing Inquiry 18 (2), 102-110.

Jokelainen M., Turunen H., Tossavainen K., Jamookeeah D. \& Coco, K., 2011. A systematic review of mentoring nursing students in clinical placements. Journal of Clinical Nursing 20, 2854-2867.

Kearney, M. 2011. A learning design for student-generated digital storytelling. Learning, Media and Technology 36(2),169-188.

Melia, K. 1984. Student nurses' construction of occupational socialisation. Sociology of Health and Illness $6(2), 132-151$.

Kelly J., Ahern, K., 2009. Preparing nurses for practice: A phenomenological study of the new graduate in Australia. Journal of Clinical Nursing 18 (6), 910-918.

Kirk C. \& Pitches J., 2013. Digital reflection: using digital technologies to enhance and embed creative processes. Technology, Pedagogy \& Education 22 (2), 213-230.

Kirk M., Tonkin E., Skirton H., McDonald K., Cope B. \& Morgan R., 2013. Storytellers as partners in developing a genetics education resource for health professionals. Nurse Education Today 33, 518-524.

Levett-Jones T., Lathlean J., McMillan M. \& Higgins I., 2007. Belongingness: A montage of nursing students' stories of their clinical placement experiences. Contemporary Nurse 24 (2), 162-174.

Li, J., Shang, L., Galatsch, M., Siegrist, J., Muller, B.H., Hasselhorn, H.M., 2013. Psychosocial work environment and intention to leave the nursing profession: A cross- 
national prospective study of eight countries. International Journal of Health Services 43 (3), 519-537.

Mann K., Gordon J. \& MacLeod A., 2009. Reflection and reflective practice in health professions education: A systematic review. Advances in Health Sciences Education 14, 595621.

Mimirinis M. \& Bhattacharya M., 2007. Design of virtual learning environments for deep learning. Journal of Interactive Learning Research 18 (1), 55-64.

Moon J., 2004. A Handbook of Reflective and Experiential Learning. Routledge Falmer, London.

Moon J. \& Fowler J., 2008. 'There is a story to be told...': A framework for the conception of story in higher education and professional development. Nurse Education Today 28, 232-239.

Paliadelis, P., Stupans, I., Parker,V., Piper,D., Gillan, P., Lea, J., Jarrott, H.M. Wilson, R., Hudson, J. \& Fagan, A . 2015. The development and evaluation of online stories to enhance clinical learning experiences across health professions in rural Australia. Collegian,22(4), 397-403

Sandelowski M., 2000. Whatever happened to qualitative description? Research in Nursing \& Health 23, 334-340.

Schön D.A., 1987. Educating the Reflective Practitioner. Jossey-Bass, San Francisco.

Schwind, J., Cameron, D., Franks, J.,Graham, C. \& Robinson, T. 2012. Engaging in narrative reflective process to fine tune self-as-instrument-of care. Reflective Practice, 13(2), 223-235. 
Stacey G. \& Hardy P., 2011. Challenging the shock of reality through digital storytelling. Nurse Education in Practice 11 (2), 159-164.

Walker A., Yong M., Pang L., Fullarton C., Costa B. \& Dunning T.A.M., 2013. Work readiness of graduate health professionals. Nurse Education Today 33, 116-122.

Wood P.J., 2014. Historical imagination, narrative learning and nursing practice: Graduate nursing students' reader-responses to a nurse's storytelling from the past. Nurse Education in Practice, http://dx.doi.org/10.1016/j.nepr.2014.05.001. (retrieved 24 December 2014).

Young L., 2007. Story-based learning: Blended content and process to learn nursing, in: Young, L., Paterson B. (Eds.), Teaching Nursing: Developing a Student-Centred Learning Environment. Lippincott Williams \& Wilkins, Philadelphia, pp.164-188. 


\title{
LEARNING FROM CLINICAL PLACEMENT EXPERIENCE: ANALYSING NURSING STUDENTS' FINAL REFLECTIONS IN A DIGITAL STORYTELLING ACTIVITY
}

\begin{abstract}
$\underline{\text { ABSTRACT }}$
This paper reports on the learning potential of a reflective activity undertaken by final year nursing students, in which they were asked to recount two meaningful events that occurred during their clinical placements over the duration of their 3-year nursing degree program and reflect on how these events contributed to their learning to become beginning level Registered Nurses ( RNs). This descriptive qualitative study gathered narratives from 92 students as individual postings in an online forum created within the University's learning management system. An analysis of the students' reflections are the focus of this paper particularly in relation to the value of reflecting on the identified events. Four themes emerged that clearly highlight the way in which these students interpreted and learned from both positive and negative clinical experiences, their strong desire to fit into their new role and their ability to re-imagine how they might respond to clinical events when they become Registered Nurses . The findings of this study may contribute to developing nursing curricula that better prepares final year students for the realities of practice.
\end{abstract}

\section{$\underline{\text { KEYWORDS }}$}

Reflection; digital storytelling; clinical placement; workplace experience; nursing student

\section{$\underline{\text { INTRODUCTION }}$}

Storytelling is a powerful education tool widely recognised in the literature (Kearney 2011; Stacey \& Hardy 2011). Brown (2015) suggests that 'If you want someone to remember 
something important, tell them a story about it.' According to Kirk and Pitches (2013) storytelling can promote deep learning by prompting reflection on practice. As Dewey (1997) explained humans learn best by reflecting on their experiences. Nurses engage with stories from patients and colleagues on a daily basis and use these to reflect on how they relate to practice issues (Christiansen, 2011; Stacey \& Hardy 2011). Digital storytelling (DS) is a new variant of this reflective process, in which technology can be harnessed to create a safe and engaging space for storytellers to share and reflect on their experiences (Hlalele \& Brexa 2015). DS is a relatively new storytelling mode but its pedagogical value has been demonstrated (Eisenhauer , 2012), particularly its capacity to promote reflection and deep learning (Mimirinis \& Bhattacharya, 2007). The aim of the study discussed in this paper was to use an online learning platform to gather final year nursing students' stories from clinical practice to better understand what was meaningful for them and whether reflecting on their chosen events contributed to learning for future practice situations. This article reports the results of an analysis of the students' reflections as they anticipated their transition to beginning level registered nurse $(\mathrm{RN})$ practice.

\section{BACKGROUND}

Storytelling has been used as a powerful educational medium in many professions (Kirk et al., 2013). Its value in nursing education has been clearly recognised (Crookes et al., 2013; Diekelmann, 2001; Haigh \& Hardy, 2011; Ironside, 2006; 2002; Moon \& Fowler, 2008; Stacey and Hardy 2011; Wood, 2014; Young, 2007) as both an educational tool and as means of supporting students to reflect on and re-imagine practice (Paliadelis et al., 2015; Wood, 2014). Reflection is a significant aspect of understanding and developing practice (Mann et al., 2009; Moon, 2004; Schön, 1987) and personal narratives of reflection on previous events can deepen emotional awareness (Arielli, 2013; Edwards, 2014; Hunter \& Hunter, 2006) and 
help with making informed choices that build on previous experiences (Dewey, 1997). In the 1980s, Melia (1984) made the point that nurses' ability to socialise into the profession required a compromise between their educational and service (clinical) experiences, in this paper we suggest that reflecting on clinical events can assist in this process. Schwind et al. (2011:225) state that ' by telling, reflecting and reconstructing events we gain the potential to transform our lives, and consequently the lives of those in our care'. Denzin (2014:53) also suggests that reflecting on events as stories can lead to illuminative or 're-lived epiphanies', which may be turning points in people's lives and provide the opportunity to better understand our interpretations. The notion that reflection assists in reconstructing events was of significance when considering nursing students reflections of clinical experiences and what such reflections might contribute to their learning for future practice. The challenge for educators is to understand how best to use refection to prompt learning and improve practice (Gidman, 2013). Callens and Elen (2015) explain that effective reflective learning is evident when the reflective narrative includes emotional, technical, moral and political elements.

Stacey and Hardy (2011:164) found the use of digital stories to prompt reflection is particularly relevant for novice nurses and these authors encourage the use of storytelling to 'enable student to be better prepared for the real world of clinical practice'. Jokelainen et al (2011) and Levett-Jones et al. (2007) add that clinical learning environments must be supportive if they are to assist novice nurses to 'fit in' to a new work environment. Walker et al. (2013) also stress the importance of providing support for novice nurses to enable them to become work ready and develop the level of resilience and flexibility needed to cope with the complexities of the modern health workplace. 
Without positive role-modelling and a supportive learning environment novice nurses are at risk of experiencing anxiety and negativity in the workplace, which may even result in them leaving the profession prematurely (Jackson et al., 2011; Li et al., 2013; Stacey \& Hardy, 2011). The aim of the study discussed in this paper was to explore whether reflecting on previous clinical events could better support students to make the transition into practice and so final year students were the target population. Students were given a structured format in which to recounted two events from their previous clinical placement experiences. In a final posting, the students were asked to reflect on both of these events and identify the elements that they felt would shape their future practice as beginning RNs. It is these reflections that are the focus of this paper.

\section{RESEARCH DESIGN}

This study used a qualitative descriptive methodology to analyse the students' stories and reflections. Sandelowski (2000:336) explained that this is a valuable methodology when researchers want to 'stay closer to their data and to the surface of words and events. Surface readings should not be considered superficial, or trivial and worthless'. Ethical approval for this study was granted by the Human Research Ethics Committee of the university. Following completion and grading of the students' work, all students were given an information sheet and consent form, and invited to allow their data to be used for this study; 92 of the 123 students consented to their de-identified stories and reflections being used for this study.

The Human Research Ethics Committee embargoed use of the data for one year following data collection, to reduce any potential risk that data could be linked to any specific student, clinical setting or situation. After 1 year the archived data was downloaded from the learning management system and analysed thematically. 
The students' reflections were analysed by each researcher separately, to identify major themes in the reflective narratives. The analyses were then discussed as a group, and where any differences occurred, the best representation of the themes in the reflections was agreed.

The quality and depth of the reflections meant that a significant amount of data was analysed. Students reflected on a number of aspects of the events they described, identifying a range of ethical, professional, technical, political and clinical issues they encountered on clinical placement. The depth of the reflections were consistent with Callens and Elen's (2015) understanding of what constitutes a critical reflection. While an analysis of the content of the two clinical events on which the student reflections were based is beyond the scope of this paper, focusing on the reflective narratives highlights the core issues the students focused on in their stories.

\section{$\underline{\text { RESULTS }}$}

This section describes the four themes that emerged from the thematic analysis of the students' reflections: 1) recognising the impact of experience, 2) understanding workplace complexity, 3) confirming career choices, and 4) transitioning to RN practice.

\section{Theme 1:Recognising the impact of experience}

This theme captures the participants' reflections on the significance of the events they described, and what these may mean for their future practice. The students clearly learned from a range of difficult situations and often re-imagined the events, based on what they learned from them. The participants also wrote about how they developed an awareness of the value of reflecting on their experiences to inform future practice. 
Many of the students' reflections made it clear that the events they chose to describe left a 'lasting impression'. These were predominantly stories of difficult situations or events. Students used powerful descriptors in relating them, such as 'confronting', 'extraordinary', 'alarming' and 'intimidating'. Students wrote that they experienced 'shock, puzzlement and confusion', or felt 'really scared' or 'astounded', as part of their reflections on the significance of the chosen events.

Students frequently remarked that difficult events were ultimately positive for learning. One believed that it was because it caused a 'strong emotional reaction'. The following comments show a consistent thread in students' recognition of what they learned from negative experiences:

The clinical event was a negative experience but has influenced my nursing practice in a positive way.

These experiences highlighted not only the type of nurse I want to be, but more importantly the type of nurse "I do not want to be", therefore I have chosen to extract the positives about what I have gained, rather than stew or dwell on what had taken place.

Even if the professional practice I encounter is not professional and does not adhere to any applicable policies or processes, it will still inform my future practice because I am learning what not to do.

The two incidents influenced and informed my view not only on how nurses in general should deliver care but how I personally want to deliver care, how I would manage such situations, and the kind of nurse I would like to be. 
From these two unacceptable cases I have learnt such fundamental concepts of nursing, especially involving patient advocacy. I have learnt to have a voice and an opinion, to speak when I do not think something is acceptable.

A number of positive incidents were also captured. As one student commented:

Although I had experienced and witnessed bad clinical incidents they have [been] outweighed by copious amazingly good experiences. To me, I have learnt most from the bad experiences than those of good but have been inspired by amazing nurses who I wish I could be like one day.

In their reflections many of the students re-imagined the events and identified skills or attributes they felt they needed to become effective nurses. Advocacy was a significant factor discussed by many of the students. In one of the narratives a student questioned her motives for not speaking up:

Ifelt fearful of the repercussions that might lie ahead when challenging someone in a higher position. With this said, I can now see that I only had my own interest at heart, when I should have been a better advocate and questioned the care that was received.

Similarly others said:

As a student in this situation it is hard to speak up and say something as we are concerned of the ramifications that may occur. However, on reflection I realise that the patient's health may have been at risk, and I probably should have reported it.

I was freaking out on the inside ... I was extremely uncomfortable. I didn't want to be labelled the student nurse that thought she knew better than the staff. 
One participant wondered why it was difficult to speak out when the situation involved another nurse.

I have never had a problem advocating for patients with medical officers or other members of the interdisciplinary team and pride myself on this. However, when it came to confronting a fellow nursing colleague about their behaviour, I was unable to do so. I wonder if this is to do with peer pressure, or the cultural norms of the nursing profession. Do we stick together because we are on the same "side"? ... It is an area I need to reflect on more thoroughly and come to understand what my feelings were ... This is not a trait I wish to take into my beginning practice.

A number of the other reflections enabled students to consider whether their initial reaction was the right one or needed to be modified.

I may have conceived these actions as inappropriate due to being shocked ... [and] this may have resulted in incorrectly perceiving this in a negative or incorrect manner.

One incident made me feel as though I had caused the medication error. I have reflected upon the experience and realised that I was not to blame.

Overall, the students noted that a change in their appreach to practice. reflecting on clinical placement events gave them 'confidence and courage' instead of being 'an overwhelmed student in the background with a sense of powerlessness'. Learning from RNs' 'strengths and making them your own', and acknowledging their own 'mistakes and weaknesses', were seen as highly valuable outcomes of reflecting. Students displayed evidence of experiencing re-lived epiphanies, as described by Denzin (2014). 
Students also commented that the learning activity had reinforced for them the value of reflection. One said:

I have just had a light bulb moment. I can now come to understand the importance of reflective journal writing....I have not only learnt from this exercise in regards the clinical incidents, I have learnt the importance of reflection.

\section{Theme 2: Understanding workplace complexity}

In the second theme, students focused on the complexity of the workplace and the organisational factors influencing practice. If their stories described mistakes (such as potential medication errors) or what they perceived as unprofessional behaviour (such as disrespect to patients), they acknowledged that these were not necessarily deliberate and that many factors contributed to these incidents:

I don't believe the staff intentionally meant to be disrespectful; they were being task oriented and did not identify their behaviour as detrimental to achieving optimal care.

Patient load, time constraints and staffing issues were frequently mentioned as contributing factors:

Major precipitating factors in this event were increased workload and inadequate staffing.

It is also essential that I take into consideration the reasons as to why these incidents occurred, such as patient loads and inadequate staffing, time restraints and lack of education. 
One student thought an incident might have been 'the result of something external to work that the nurse brought with them' and that if the nurse had had 'an opportunity to disclose and discuss their stresses', it might not have occurred. However, personal contributing factors were not always seen in this light:

Reflecting on the situation and going through the events it was evident that my registered nurse not only had a heavy patient load she was extremely exhausted from the night before and stated she had little sleep if any at all....She did not carry out her duty of care.... Her best on the day was not good enough and could have resulted in death. Duty of care to herself and her patients was compromised and she was only lucky this mistake was not deadly.

\section{Theme 3: Confirming career choices}

The third theme captures the participants' commitment to the nursing profession. For many of the students this was about being inspired by others during their placements, while for some it was about acknowledging any doubts about their career choice and about developing confidence in their ability to function as beginning level RNs.

Students sometimes reflected that their clinical placement experiences confirmed their decision to become a nurse. This was often due to an 'inspiring' situation or registered nurse.

It was inspiring and something I hope I can take with me wherever I go.

I think at some stage of our working, or student, life we are touched by someone that truly inspires us to forge ahead and strive to obtain the highest of goals.

This is the kind of nurse I want to be. 
One student's experience of a medical emergency was a significant moment in confirming the choice of nursing as a career:

One of the professional issues I encountered was an extremely positive experience for me and one I am sure in years from now I will look back and it will stick out as a major learning curve and point in my life that I was sure a career in nursing was exactly what I wanted to do.

Sometimes an incident in clinical placement led students to reflect on whether they had made the right their career choice.

It made me question the reason as to why I wanted to be a registered nurse.

I would find myself questioning why it was that I was studying the degree in the first place! This is a blunt statement to make, however I feel it is a necessary component to outline my experiences as a student nurse.

\section{Theme 4: Transitioning to RN practice}

It was very clear in all the reflections that these students understood some of the challenges they would face as they commenced a nursing career. For some, the responsibilities they would assume as RNs were rather daunting. However, the reflections suggested that the participants were acutely aware of the unpredictability of modern nursing practice and the value of reflecting on events to inform future practice. Understandably these participants also commented on their nervousness about 'fitting in' to the clinical work environment and developing a sense of belonging. They also looked forward to their role in supporting nursing students in the future.

Reflecting on clinical placement events gave these students a sense of the expectations and the 'not so obvious challenges' of commencing RN practice. They worried about the 
degree of responsibility they would have - 'people's lives will be in my hands' - as well as how quickly and easily clinical situations could change and 'lives can be lost'.

Observing these clinical incidents has shown to me how precious life is and how unexpectedly things may evolve.

The students identified that reflecting on their experiences helped them to developed a clear understanding that flexibility, adaptability and a calm approach were needed in managing rapidly changing situations.

Nursing is a profession with many surprises and it's important as a RN to be flexible and adapt to changing situations.

Through witnessing this event unfold and acknowledging all the factors associated I realised there is immense value in just stopping and taking a deep breath. Taking a deep breath, centring myself, taking the time to prioritise care and the tasks at hand.

Several were 'fearful' of the responsibility and accountability of RN practice.

Transitioning from a student nurse to a Registered Nurse $(R N)$ can be quite scary and quite concerning in regards to undertaking an autonomous role and developing professional credibility. Expectations of a new graduate nurse can be quite overwhelming.

Overall, reflection on clinical placement experiences supported students 'to be the confident, capable and professional nurse' they were aspiring to be. Many were confident that they would successfully transition to RN practice. 
I now understand I am a strong and capable individual who is confident in my ability to nurse and care for patients professionally.

They also realised the incremental nature of developing skills and confidence.

Also I find as an important aspect as a newly Registered Nurse is to appreciate that out knowledge base is limited and will constantly develop with exposure to the world of nursing. It is important that at times it is appropriate to question if unsure why things are occurring.

I almost made myself physically sick because I was so worried that I would be judged on the amount of time it takes me... I have started to become less critical of myself and ... I am hoping that I will challenge my thought processes as my practice develops.

Students reflected on the difference between being a student or an RN in a practice context. They particularly emphasised that they needed to be accepted before trying to influence change. 'Fitting in' was an important first step. The students felt that it was very important to 'fit in with the culture of the facility'.

Fitting in is almost a core element to successful progression and professional development as a new nurse.

I acknowledge that it will take me a month or so to settle into my new work environment but I am confident that I will then be able to speak up about issues that concern me.

They knew that as students they had responsibility 'to identify wrong practices' but believed that as an $\mathrm{RN}$ they would have 'a greater level of power to change and apply the 
appropriate practice'. Nevertheless, they felt that 'gumption' would be needed to advocate for patients or practice changes:

As new RNs they might sometimes 'doubt [their] clinical knowledge and confidence' and therefore needed strategies to manage this and support to advocate for changes. One strategy was to 'look for a group of mentors' with similar values who could 'assist and guide' their professional development and practice. They needed, for example, to 'form relationships with peers, prioritise and be organised', to 'listen and be confident in interacting with other members of staff' and 'continue to learn'. Many students identified particular skills they wished to develop further in their beginning RN practice, such as being assertive.

In particular, all the students reflected on how, as RNs, they hoped to work with and inspire nursing students. They believed their own experience on clinical placement would help them to interact effectively with students. They knew the 'pressures' students faced so would 'help relieve these stresses'. From this, they emphasised several aspects:

This incident has taught me the importance of communicating with the student, discovering their thoughts and feelings toward the placement and working together to achieve identified learning objectives.

Students needed to feel 'part of the team' and that they could 'share their knowledge and ideas without repercussions'.

I know now through this reflection that I can be a good mentor because I can reflect upon my own feelings as a student nurse and hopefully make other students' experiences more positive. 
An important point was not to 'put a student in a position which you never felt comfortable in when you were a student'. Several students commented that their experience had made them think that 'nurses eat their young'.

This experience has left me with a feeling that I still find uncomfortable, when thinking about the incident. After this experience I understand the phrase "nurses eat their young".

I will never treat a student the way I was treated ... The saying "nurses eat their young", I heard this many times and have even said it myself.

\section{DISCUSSION}

This discussion links the themes identified in the students' final reflections with the literature on clinical learning, transition to practice and work readiness, and considers the value of reflective storytelling to prompt learning.

The themes that emerged from the students' reflections focused on the overall impact of the clinical placement events they described, and their insights into the realities of the workplace, choice of nursing as a career, and transition to beginning RN practice, including the importance of 'fitting in'. These clearly resonate with the themes identified in relevant literature.

Students' comments on supportive and unsupportive clinical learning environments are reflected in a number of studies on clinical placement experiences which note that a supportive learning environment is a key feature in facilitating students' learning (Jokelainen et al., 2011; Levett-Jones et al., 2007). As with students' comments in our study, the systematic review of clinical placement mentoring by Jokelainen et al (2011) identified the importance of attending to students as individual learners to understand their learning needs. 
Similarly, the mutual relationship between student and mentor was important. This relates closely to students' comments on the significance of inspiring role models. However, in our study the students also strongly believed that negative role models could have a positive influence on their practice and they demonstrated how reflections on negative events allowed them to re-imagine them more positively. Their reaction to what they perceived as poor practice or disrespectful work relationships supports Kirk et al (2013) findings that such events can prompt 'professional shame'. As Hunter and Hunter (2006) have noted, reflection supports students to discern their own style of practice and is therefore an important aspect of role identity and acquisition.

Students had concerns about the uncertainty of the workplace, seen for example in the need for rapid and flexible responses to changing patient conditions, and they recognised the need to manage these situations effectively. This links with Walker et al's (2013) description of resilience and flexibility as personal characteristics of work readiness. Students' acknowledgement of the complexity of the workplace and the impact of patient load, time constraints and inadequate staffing, also connects with Walker et al's (2013) description of organisational acumen as another key feature of work readiness. Several students noted that clinical placement experiences, particularly inspiring role models or satisfaction with their own practice, confirmed their decision to enter nursing as a career. As Jokelainen et al (2011) found, mentoring by positive role models strengthens student's development of professional attributes and identity. Some participants indicated they felt some doubts about their choice of career. This is not unexpected given that there is significant evidence in the literature that the global nursing shortage is partly attributed to attrition of nurses from the workforce due to staff shortages, poor skill mix and job strain (Li et al., 2013). 
An important aspect of students' reflections is their anticipation of the transition to beginning RN practice that identified clear concern about the need to 'fit in'. Building on the work of Melia (1984), Levett-Jones et al's (2007) study of belongingness in clinical placement also emphasised the importance of students' need for connectedness and fit. This links with Walker et al's (2013) description of social intelligence as a key feature of work readiness, including effective communication, teamwork and management of conflict. Students' reflections indicated that they had identified strategies they hoped to use to support the balance between fitting in and making changes, including finding mentors and likeminded colleagues. Similarly, Walker et al (2013) described the importance of seeking support as an element in work readiness.

Students strongly identified the importance of being a good mentor and role model to students in their future RN practice. Jokelainen et al (2011) noted that 'students want to be treated as individuals and colleagues during placement learning' (p.2864) and that achieving a degree of collegiality is desirable within the mentoring relationship. This is clear in students' reflections in our study. However, their comments were based more often on negative experiences than on examples of positive role models. Students felt that reflecting on difficult clinical placement experiences enabled them to identify how they could be better mentors for future students. They would communicate with students, consider their individual goals and help them feel part of the team. Their shock at being on the receiving end of disrespectful or abusive behaviour from nurses and others is reflected in other studies (Jackson et al., 2011; Stacey \& Hardy 2011) and is part of the emotional work arising in clinical placement experience (Arielli, 2013). Students did not want to belong to a profession that 'eats its young'. This is recognised as an issue within nursing and is related in the literature to horizontal violence, bullying and burnout ( Kelly \& Ahern, 2009). 
Literature on reflective storytelling, including digital storytelling, identifies a range of benefits (Haigh \& Hardy, 2011; Kearney 2011; Mimirinis \& Bhattacharya, 2007; Stacey \& Hardy 2011). Particularly relevant to this study is that telling stories and then reflecting on their meaning enabled these students to make sense of their experiences (Moon, 2004). As suggested by Stacey and Hardy (2011) and Schwind (2011), and based on the earlier work of Dewey (1997) reflecting on our experiences provides opportunities to shape future practice. The iterative nature of this digital storytelling and reflective learning activity, provided an opportunity for these students to learn lessons they considered valuable for their future practice (Moon, 2004; Moon \& Fowler, 2008). The great majority of these students showed a deep engagement in reflecting on their stories. They included a range of emotional, technical, moral and political elements in their reflection, which Callen and Elan (2015) suggest demonstrates deep and effective reflection. While Moon and Fowler (2008) warn that when recalling past events students might modify their accounts to meet suit teacher expectations, in this study the students' reflections contained both positive and negative appraisals of their performance.

In this study, the content of the students' stories were not 'graded' and students needed only to show that they had engaged reflectively with their stories in order to pass this task. As Moon and Fowler (2008) noted, 'the very act of telling [a story] has educational value and may be more significant than the content' (p.234). In this study we suggest that this was certainly the case. In addition, the authenticity of students' stories and reflections, and their willingness to have them used for this study, indicates they were not trying to merely provide what they thought lecturers were expecting.

Mann et al's (2009) systematic review of reflection in health profession education identified reflection as an essential characteristic of professional competence, while Schwind 
et al (2013) suggest that the ability to reflect is vital in helping professions such as nursing. Students' reflections in this study demonstrated that they had engaged effectively with their stories of clinical placement events and had learnt from them in ways that would inform their beginning practice as RNs.

The main limitation of this study is that because this study drew on text-based narratives that were entered into an online learning management system by final year nursing students and the use of the data was embargoed for 12 months, no further discussion or clarification was possible with the participants about their narratives. However, the students' online postings provided rich research material for this qualitative descriptive study.

\section{CONCLUSION}

This paper described a research study in which the participants described two events of their choosing from their clinical experiences and reflected on what these events taught them in relation to making the transition from student to registered nurse . It is suggested that this approach allowed the participating students to consider the links between their knowledge base, their individual experiences and the realities of clinical practice, as across all the stories it was clear that students had thought deeply about the events they described and reflected on how these might shape their practice as beginning level RNs. 


\section{$\underline{\text { REFERENCES }}$}

Arielli, D., 2013. Emotional work and diversity in clinical placements of nursing students. Journal of Nursing Scholarship 45 (2), 192-201.

Brown, S. 2015. The power of story. Computer. September, 82-83.

Callens, C. \& Elan, J. 2015. Does a structured methodology support pre-service teachers more to reflect critically than an unstructured? Reflective Practice 16(5), 609-622.

Christiansen A., 2011. Storytelling and professional learning: A phenomenographic study of students' experience of patient digital stories in nurse education. Nurse Education Today 31, 289-293.

Crookes K., Crookes P. \& Walsh, K., 2013. Meaningful and engaging teaching techniques for student nurses: A literature review. Nurse Education in Practice 13 (4), 239243.

Denzin N., 2014. Interpretive Autoethnography, second ed. Sage, Los Angeles.

Dewey, J. (1997). Experience and education. New York, NY: Touchstone Edition. (Original work published 1938)

Diekelmann N., 2001. Narrative pedagogy: Heideggerian hermeneutical analyses of lived experiences of students, teachers, and clinicians. Advances in Nursing Science 23 (3), 53-71.

Edwards S.L., 2014. Using personal narrative to deepen emotional awareness of practice. Nursing Standard 28 (50), 46-51.

Eisenhauer J., 2012. Behind closed doors: The pedagogy and interventionist practice of digital storytelling. Journal of Curriculum \& Pedagogy 9 (1), 7-15. 
Gidman G., 2013. Listening to stories: Valuing knowledge from patient experiences. Nurse Education in Practice 13 (3), 192-196.

Haigh C., Hardy P., 2011. Tell me a story - a conceptual exploration of storytelling in healthcare education. Nurse Education Today 31, 408-411.

Hlalele, D. \& Brexa, J. 2015. Challenging the narrative of gender socialisation: Digital storytelling as an engaged methodology for the empowerment of girls and young women. Agenda, 29(3), 79-88.

Hunter L.P., Hunter L.A., 2006. Storytelling as an educational strategy for midwifery students. Journal of Midwifery \& Women's Health 51 (4), 273-278.

Ironside P.M., 2006. Using narrative pedagogy: Learning and practising interpretive thinking. Journal of Advanced Nursing 55 (4), 478-486.

Jackson, D., Hutchinson, M., Everett, B., Mannix, J., Peters, K., Weaver, R. \& Salamonson, Y., 2011. Struggling for legitimacy: Nursing students' stories of organisational aggression, resilience and resistance. Nursing Inquiry 18 (2), 102-110.

Jokelainen M., Turunen H., Tossavainen K., Jamookeeah D. \& Coco, K., 2011. A systematic review of mentoring nursing students in clinical placements. Journal of Clinical Nursing 20, 2854-2867.

Kearney, M. 2011. A learning design for student-generated digital storytelling. Learning, Media and Technology 36(2),169-188.

Melia, K. 1984. Student nurses' construction of occupational socialisation. Sociology of Health and Illness 6 (2), 132-151. 
Kelly J., Ahern, K., 2009. Preparing nurses for practice: A phenomenological study of the new graduate in Australia. Journal of Clinical Nursing 18 (6), 910-918.

Kirk C. \& Pitches J., 2013. Digital reflection: using digital technologies to enhance and embed creative processes. Technology, Pedagogy \& Education 22 (2), 213-230.

Kirk M., Tonkin E., Skirton H., McDonald K., Cope B. \& Morgan R., 2013. Storytellers as partners in developing a genetics education resource for health professionals. Nurse Education Today 33, 518-524.

Levett-Jones T., Lathlean J., McMillan M. \& Higgins I., 2007. Belongingness: A montage of nursing students' stories of their clinical placement experiences. Contemporary Nurse 24 (2), 162-174.

Li, J., Shang, L., Galatsch, M., Siegrist, J., Muller, B.H., Hasselhorn, H.M., 2013. Psychosocial work environment and intention to leave the nursing profession: A crossnational prospective study of eight countries. International Journal of Health Services 43 (3), $519-537$

Mann K., Gordon J. \& MacLeod A., 2009. Reflection and reflective practice in health professions education: A systematic review. Advances in Health Sciences Education 14, 595621.

Mimirinis M. \& Bhattacharya M., 2007. Design of virtual learning environments for deep learning. Journal of Interactive Learning Research 18 (1), 55-64.

Moon J., 2004. A Handbook of Reflective and Experiential Learning. Routledge Falmer, London. 
Moon J. \& Fowler J., 2008. 'There is a story to be told...': A framework for the conception of story in higher education and professional development. Nurse Education Today 28, 232-239.

Paliadelis, P., Stupans, I., Parker,V., Piper,D., Gillan, P., Lea, J., Jarrott, H.M. Wilson, R., Hudson, J. \& Fagan, A . 2015. The development and evaluation of online stories to enhance clinical learning experiences across health professions in rural Australia. Collegian,22(4), 397-403

Sandelowski M., 2000. Whatever happened to qualitative description? Research in Nursing \& Health 23, 334-340.

Schön D.A., 1987. Educating the Reflective Practitioner. Jossey-Bass, San Francisco.

Schwind, J., Cameron, D., Franks, J.,Graham, C. \& Robinson, T. 2012. Engaging in narrative reflective process to fine tune self-as-instrument-of care. Reflective Practice, 13(2), 223-235.

Stacey G. \& Hardy P., 2011. Challenging the shock of reality through digital storytelling. Nurse Education in Practice 11 (2), 159-164.

Walker A., Yong M., Pang L., Fullarton C., Costa B. \& Dunning T.A.M., 2013. Work readiness of graduate health professionals. Nurse Education Today 33, 116-122.

Wood P.J., 2014. Historical imagination, narrative learning and nursing practice: Graduate nursing students' reader-responses to a nurse's storytelling from the past. Nurse Education in Practice, http://dx.doi.org/10.1016/j.nepr.2014.05.001. (retrieved 24 December 2014). 
Young L., 2007. Story-based learning: Blended content and process to learn nursing, in:

Young, L., Paterson B. (Eds.), Teaching Nursing: Developing a Student-Centred Learning Environment. Lippincott Williams \& Wilkins, Philadelphia, pp.164-188. 


\section{$\underline{\text { Highlights }}$}

Storytelling is a powerful education tool and its value in nursing education is widely recognised in the literature. Storytelling can promote deep learning in reflection on practice. Nursing students can engage with stories from patients, fiction or other nurses and reflect on how these relate to practice issues, or can recount their own stories as a foundation for reflection. Digital storytelling (DS) is a new variant of this reflective process. The aim of this study was to analyse final year nursing students' reflective digital storytelling about two clinical placement experiences. Students recounted and reflected on their experiences in three online postings during their final semester of study in a nursing degree program in an Australian university. This article reports the results of an analysis of their final reflections as they anticipated their transition to registered nurse $(\mathrm{RN})$ practice. 
Conflict of interest statement for revised article

Reference number: NEP-D-15-00094

Title: LEARNING FROM CLINICAL PLACEMENT EXPERIENCE: ANALYSING NURSING STUDENTS' FINAL REFLECTIONS IN A DIGITAL STORYTELLING ACTIVITY

We, the authors, declare that we do not have any conflicts of interest in relation to the study or the manuscript submitted.

Authors:

Professor Penny Paliadelis ${ }^{\mathrm{a}}$

Associate Professor Pamela Wood ${ }^{\mathrm{b}}$

${ }^{a}$ Corresponding author - Executive Dean, Faculty of Health, Federation University Australia, PO Box 663, Ballarat, VIC, Australia 3353. Email: p.paliadelis@ federation.edu.au, Tel: +61353276445, Mob:+61400417494

${ }^{\mathrm{b}}$ Associate Dean (Research), Faculty of Health, Federation University Australia, PO Box 663, Ballarat, VIC, Australia 3353. Email: pamela.wood@federation.edu.au 